\title{
Microsatellite genetic variation in small and isolated populations of Magnolia sieboldii ssp. japonica
}

\author{
S Kikuchi ${ }^{1,2}$ and Y Isagi ${ }^{3}$ \\ ${ }^{1}$ Department of Forest Genetics, Forestry and Forest Products Research Institute, Kukizaki, Ibaraki 305-8687, Japan; ${ }^{2}$ Centre for \\ Ecological Research, Kyoto University, Kamitanakami Hiranocho, Otsu, Shiga 520-2113, Japan; ${ }^{3}$ Faculty of Integrated Arts E \\ Sciences, Hiroshima University, 1-7-1 Kagamiyama, Higashi-Hiroshima 739-8521, Japan
}

\begin{abstract}
Magnolia sieboldii ssp. japonica, distributed mainly in western Japan, is restricted to high elevation areas (1000-2000 $\mathrm{m}$ above sea level) and usually forms small isolated populations. Four microsatellite loci were assayed for 19 populations from six regions spanning the range of distribution, and the levels and distribution of genetic variation were estimated. All four loci were variable, with a total of 39 alleles, but the overall level of microsatellite genetic variation was low, especially compared with a related species, $M$. obovata. Genetic structure in $M$. sieboldii was characterised by low intrapopulational genetic variation $\left(A=3.74\right.$ and $H_{\circ}=0.366$ on average) and high genetic differentiation even among regional populations. Highly significant isolation-by-distance (IBD) models at the short distance were detected. Genetic drift and limited gene flow was considered to be important
\end{abstract}

in determining the genetic structure within regions. Total genetic differentiation was remarkably high $\left(\mathrm{F}_{\mathrm{ST}}=0.488\right.$ and $\mathrm{R}_{\mathrm{ST}}=0.538$ ), suggesting genetic barriers among regions. Neighbour-joining dendrograms relating the 19 populations, and further analysis on the IBD models, revealed that a stepwise mutation model was more suited than an infinite allele model to explain the genetic differentiation among regions. It is suggested that mutation at microsatellite loci might be influential in generating the genetic differentiation among regions. These results showed the potential of hypervariable microsatellite loci to evaluate the effects of genetic drift and population isolation within regions, and to detect genetic distinctiveness, in spite of the loss of overall genetic variation in $M$. sieboldii.

Heredity (2002) 88, 313-321. DOI: 10.1038/sj/hdy/6800047

Keywords: Magnolia sieboldii; microsatellite: genetic diversity; population size; genetic drift; isolation-by-distance

\section{Introduction}

Within a species, the genetic structures of plant populations are determined by factors such as mutation, migration, selection and genetic drift. The effects of genetic drift are important when populations are small or isolated. Species consisting of such populations usually have small within-population genetic variation and large among-population differentiation (Loveless and Hamrick, 1984). Genetic information can be useful in the conservation of rare plant species, which usually consist of small and/or isolated populations. For example, the risk of extinction of a population or a species can be assessed, and the steps and priorities necessary to prevent extinction can be determined by estimating the level of genetic diversity, the effect of genetic drift, and the extent of genetic differentiation and gene flow, from genetic data (Ellstrand and Elam, 1993). However, the genetic variability of isolated or local endemic populations sometimes collapses because of severe genetic drift or historical bottlenecks; in such cases little or no genetic variation is detected in the population using genetic markers, such

Correspondence: S Kikuchi, Department of Forest Genetics, Forestry and Forest Products Research Institute, Kukizaki, Ibaraki 305-8687, Japan. E-mail: kikusato@ffpri.affrc.go.jp

Received 7 August 2001; accepted 25 November 2001 as allozymes or RAPDs (eg, Ledig and Conkle, 1983; Bauert et al, 1998; Vogel et al, 1999).

Recently, hypervariable microsatellite loci have become a popular genetic tool in population and conservation genetics. Microsatellites have such strong discriminating power that they have been utilised for parentage analysis (Dow and Ashley, 1996; Isagi et al, 2000) and detection of fine-scale genetic differentiation (van Oppen et al, 1997; Streiff et al, 1998). We would expect to find variability in severely bottlenecked or isolated populations where genetic markers, such as allozymes and RAPDs, detect little or no variation (Hughes and Queller, 1993). Microsatellites are also considered to be appropriate for surveying phylogenetic relationships among populations, although problems of size homoplasy, due to convergent mutations, remain (Valdes et al, 1993). Studies have shown the high efficiency of microsatellites in distinguishing populations or groups of populations (eg, Rowe et al, 1998; Widmer and Schmid-Hempel, 1999). These applications make microsatellites suitable tools for the conservation and population genetics of rare and/or isolated species. In spite of this potential, there is still a paucity of data of microsatellite variation in plant populations.

In this study, microsatellite variation in a rare and patchily distributed plant, Magnolia sieboldii C. Koch ssp. japonica Ueda, was surveyed across its distributional range. $M$. sieboldii ssp. japonica is a deciduous shrub that 
reaches a height of $3 \mathrm{~m}$. It is distributed mainly in western Japan, extending from Yakushima Island to northern Kanto. Shrubs of M. sieboldii in Japan grow at high elevations in mountainous regions, $1000-2000 \mathrm{~m}$ above sea level. They live on restricted areas such as narrow stony ridges, among rocks, or on the edges or in openings of upper cool-temperate-deciduous to subalpine-coniferous forests; and they can be found in limestone or serpentine areas (Ueda, 1980). Shrubs of M. sieboldii usually form small isolated populations.

The aim of this study was to survey microsatellite variation within and among populations of $M$. sieboldii and to assess the usefulness of microsatellites as a tool in the conservation of small and isolated populations of $M$. sieboldii. The focus of the study was on the level of microsatellite variability within populations, the extent of hierarchical genetic differentiation at intrapopulation, regional, and whole-species levels, and the comparison of genetic relationships with geographical relationships among populations.

\section{Materials and methods}

\section{Sampling sites}

Nineteen populations were sampled across six regions (Mts Hodaka, Akasawa Recreational Forest, Mts Ohmine, Mts Ishizuchi, Mt Kanmuri, and Mt Kunimi) throughout the distribution range of $M$. sieboldii (Figure 1). The populations of $M$. sieboldii were usually small and isolated, and consisted typically of only tens of shrubs. An exception was the Hakkyougatake population (OMN1), which consisted of hundreds of shrubs. For each population leaves were sampled from 11 to 56 shrubs. In all, 658 samples

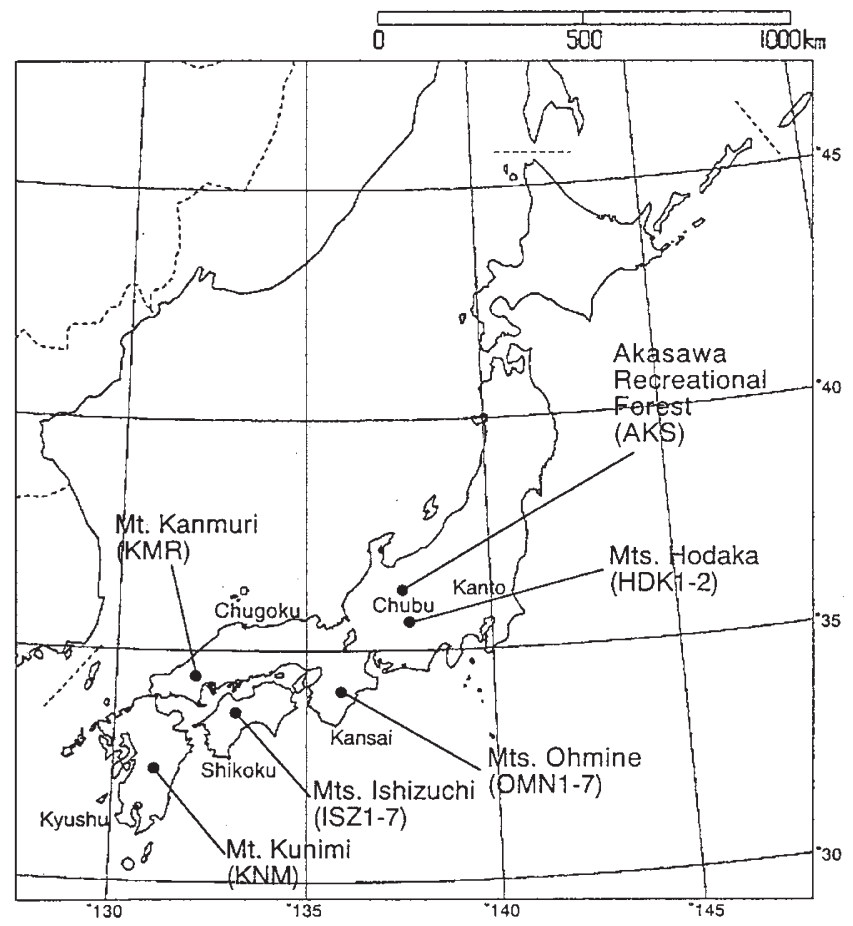

Figure 1 Distribution of the sample populations of Magnolia sieboldii, with population identification codes in parentheses, according to Table 1. were collected (Table 1). Intensive sampling was carried out within the Ishizuchi and Ohmine mountain ranges; seven populations were sampled in each of these regions. Additionally, two populations were sampled in the Hodaka mountain range. Populations within regions were $0.3-14 \mathrm{~km}$ apart.

\section{DNA isolation and microsatellite analysis}

DNA was extracted from leaf materials using a CTAB method (Milligan, 1992). Four microsatellite loci (M6D3, M6D4, M10D8, M17D5) were analysed in this study, selected from 11 loci identified by Isagi et al (1999) in $M$. obovata. These primer pairs had been found applicable to most of the other Magnolia species in Japan (Isagi et al, 1999). PCR reactions were carried out as described in Isagi et al (1999). The PCR products were electrophoresed on the ABI 377 instrument, and the sizes were determined using Genescan ${ }^{\mathrm{TM}}$ analysis software.

\section{Data analysis}

For each population, genetic polymorphism was measured as the mean number of alleles per locus (A), observed heterozygosity $\left(\mathrm{H}_{\mathrm{o}}\right)$ and heterozygosity expected from Hardy-Weinberg assumptions $\left(\mathrm{H}_{\mathrm{e}}\right)$. Weir and Cockerham's F IS $_{\text {S }}$ (Weir and Cockerham, 1984) was calculated for each population by using the FSTAT program (Goudet, 1995). The significance of $F_{I S}$ was tested based on randomisation. $P$-values, which gave the probability that the null hypothesis $\left(\mathrm{F}_{\mathrm{IS}}=0\right)$ was true, were computed through 1000 random permutations.

The interpopulational genetic differentiation was estimated by calculating fixation indices based on an infinite allele model (IAM) and a stepwise mutation model (SMM). For the former, Weir and Cockerham's $\mathrm{F}_{\mathrm{ST}}$ values were calculated with the TFPGA program (Miller, 1997). For the latter, the $\mathrm{R}_{\mathrm{ST}}$ CALC program (Goodman, 1997) was used to calculate Slatkin's $\mathrm{R}_{\mathrm{ST}}$ (Slatkin, 1995). One thousand bootstraps for all loci gave the $95 \%$ confidence intervals to $\mathrm{F}_{\mathrm{ST}}$ and $\mathrm{R}_{\mathrm{ST}}$. In addition, population pairwise $F_{\mathrm{ST}}$ and $R_{\mathrm{ST}}$ values were estimated using the programs FSTAT and Microsat (Dr E Minch, Department of Genetics, Stanford University, USA, http://lotka. stanford.edu/distance.html).

To evaluate spatial genetic structure among populations, mean pairwise $\mathrm{F}_{\mathrm{ST}}$ and $\mathrm{R}_{\mathrm{ST}}$ values between populations within mountain ranges, and between populations belonging to different regions, were calculated separately. An isolation-by-distance (IBD) model was tested by regressing the population pairwise $\mathrm{F}_{\mathrm{ST}}$ and $R_{\mathrm{ST}}$ against the $\log _{10}$ value of the geographical distances between populations.

Unrooted dendrograms of populations were constructed using the neighbour-joining method, as implemented in the program PHYLIP (Felsenstein, 1989). Nei's standard distance D (Nei, 1978) and Goldstein's delta-mu square $(\partial \mu)^{2}$ (Goldstein et al, 1995), based on an SMM, were calculated as genetic distances, using Microsat.

A spatial autocorrelation analysis was performed for the largest population, OMN1, to determine intrapopulation spatial genetic structure. All of 52 sampled shrubs, covering most part of this population (about $0.4 \mathrm{ha}$ ), were mapped, and a distance matrix among the shrubs was constructed. Distance classes were set for $5 \mathrm{~m}$, and then 
Table 1 Locations and identification codes of the 19 sampled populations of Magnolia sieboldii

\begin{tabular}{|c|c|c|c|c|c|}
\hline Locality & Code & $\begin{array}{l}\text { Longitude } \\
\quad\left({ }^{\circ} N\right)\end{array}$ & $\begin{array}{l}\text { Latitude } \\
\quad\left({ }^{\circ} \mathrm{E}\right)\end{array}$ & $\begin{array}{l}\text { Altitude } \\
\text { (m) }\end{array}$ & No. of samples \\
\hline $\begin{array}{l}\text { Akasawa Recreational Forest, Chubu } \\
\text { District }\end{array}$ & AKS & 35.7 & 137.6 & 1140 & 31 \\
\hline \multicolumn{6}{|l|}{ Mts Hodaka, Chubu District } \\
\hline Hidarimata Path & HDK1 & 36.3 & 137.6 & 1300 & 35 \\
\hline Migimata Path & HDK2 & 36.3 & 137.6 & 1520 & 45 \\
\hline \multicolumn{6}{|l|}{ Mts Ohmine, Kansai District } \\
\hline Mt Hakkyougatake & OMN1 & 34.2 & 135.9 & 1900 & 52 \\
\hline Mt Misen & OMN2 & 34.2 & 135.9 & 1880 & 13 \\
\hline Mt Misen & OMN3 & 34.2 & 135.9 & 1800 & 41 \\
\hline Mt Misen & OMN4 & 34.2 & 135.9 & 1740 & 56 \\
\hline Mt Misen & OMN5 & 34.2 & 135.9 & 1600 & 41 \\
\hline Mt Daihugen & OMN6 & 34.2 & 135.9 & 1770 & 28 \\
\hline Mt Sanjougatake & OMN7 & 34.2 & 136.0 & 1530 & 14 \\
\hline \multicolumn{6}{|l|}{ Mts Ishizuchi, Shikoku District } \\
\hline Mt Ishizuchi & ISZ1 & 33.8 & 133.1 & 1960 & 21 \\
\hline Mt Iwaguro & ISZ2 & 33.8 & 133.2 & 1740 & 11 \\
\hline Mt Tebako & ISZ3 & 33.7 & 133.2 & 1800 & 30 \\
\hline Mt Tebako & ISZ4 & 33.7 & 133.2 & 1800 & 51 \\
\hline Mt Kamegamori & ISZ5 & 33.8 & 133.2 & 1700 & 31 \\
\hline Mt Kamegamori & ISZ6 & 33.8 & 133.2 & 1890 & 51 \\
\hline Mt Kanpusan & ISZ7 & 33.8 & 133.3 & 1700 & 24 \\
\hline Mt Kanmuri, Chugoku District & KMR & 34.5 & 132.1 & 1320 & 29 \\
\hline \multirow[t]{2}{*}{ Mt Kunimi, Kyushu District } & KNM & 32.5 & 131.0 & 1730 & 54 \\
\hline & & & & Total & 658 \\
\hline
\end{tabular}

Moran's index I' was calculated for each class at each locus (Sokal and Oden, 1978).

\section{Results}

In total, 12, 8, 17 and 12 alleles were detected at loci M6D3, M6D4, M10D8 and M17D5, respectively (see Appendix). At the intrapopulation level, numbers of alleles per locus ranged from 2.00 to 6.00 , with an average of 3.74. The observed and expected heterozygosities ranged from 0.196 to 0.642 and from 0.254 to 0.652 , with averages of 0.366 and 0.430 , respectively (Table 2 ). Of the 19 populations, 17 had inbreeding coefficients greater than zero, and nine of those had significant $P$-values $(P$ $<0.05)$. Two populations with negative $\mathrm{F}_{\text {IS }}$ values, $\mathrm{KNM}$ and OMN6, had one and two loci fixed, respectively.

Population genetic differentiation was unusually high for both $\mathrm{F}_{\mathrm{ST}}(=0.488,95 \%$ CI $0.461-0.519)$ and $\mathrm{R}_{\mathrm{ST}}(=0.538$, 95\% CI 0.522-0.571). The mean values of pairwise genetic differentiation were 0.31 for $\mathrm{F}_{\mathrm{ST}}$ and 0.26 for $\mathrm{R}_{\mathrm{ST}}$ among populations within a mountain range, whereas pairwise $\mathrm{F}_{\mathrm{ST}}$ and $\mathrm{R}_{\mathrm{ST}}$ were 0.52 and 0.57 when averaged among populations belonging to different mountain ranges. Significant isolation-by-distance was revealed for both $\mathrm{F}_{\mathrm{ST}}$ (Figure 2a; $r=0.676, P<0.001$ ) and $\mathrm{R}_{\mathrm{ST}}$ (Figure $2 \mathrm{~b} ; r=$ $0.665, P<0.001)$.

We examined relationships between pairwise values of genetic differentiation and population genetic diversity averaged for each of the population pairs (Figure 3). Pairwise values of genetic differentiation were correlated with averaged $\mathrm{A}\left(\mathrm{F}_{\mathrm{ST}}: r=-0.419, P<0.0001 ; \mathrm{R}_{\mathrm{ST}}: r=\right.$ $-0.291, P=0.0001), \mathrm{H}_{\mathrm{o}}\left(\mathrm{F}_{\mathrm{ST}}: r=-0.593, P<0.0001 ; \mathrm{R}_{\mathrm{ST}}: r\right.$ $=-0.462, P<0.0001)$ and $\mathrm{H}_{\mathrm{e}}\left(\mathrm{F}_{\mathrm{ST}}: r=-0.631, P<0.0001\right.$; $\left.\mathrm{R}_{\mathrm{ST}}: r=-0.440, P<0.0001\right)$. Pairs of populations both coming from the Ohmine region depicted patterns different from other population pairs (Figure 3). Correlation was emphasised when the population pairs from the Ohmine region were removed from analysis; pairwise $\mathrm{F}_{\mathrm{ST}}$ and $\mathrm{R}_{\mathrm{ST}}$ were correlated with mean $\mathrm{A}\left(\mathrm{F}_{\mathrm{ST}}: r=-0.756, P\right.$ $\left.<0.0001 ; \mathrm{R}_{\mathrm{ST}}: r=-0.556, P<0.0001\right), \mathrm{H}_{\mathrm{O}}\left(\mathrm{F}_{\mathrm{ST}}: r=-0.794\right.$, $\left.P<0.0001 ; \mathrm{R}_{\mathrm{ST}}: r=-0.599, P<0.0001\right)$ and $\mathrm{H}_{\mathrm{e}}\left(\mathrm{F}_{\mathrm{ST}}: r=\right.$ $\left.-0.884, P<0.0001 ; \mathrm{R}_{\mathrm{ST}}: r=-0.598, P<0.0001\right)$.

On both of the neighbour-joining trees (Figure 4), the one based on $(\partial \mu)^{2}$ and the other on Nei's D, populations coming from Ishuzuchi, Ohmine, and the Chubu District, formed a group in each of these regions. However, they did not show any monophyletic clusters in each of the regions, and bootstrap values of the nodes supporting these groups were not so high. On the neighbour-joining tree based on $(\partial \mu)^{2}$, the KNM population (in the Kyusyu District) and the KMR population (in the Chugoku District) stemmed from the Ishizuchi group, and formed a cluster together as populations from southwestern Japan, while the populations from the Chubu District stemed from the Ohmine group (Figure 4a). The genetic relationships among regions agreed well with their geographic origins on $(\partial \mu)^{2}$ (Figure 1$)$. On the other hand, for Nei's D, genetic and geographic relationships among the regions did not agree (Figure $4 b$ ).

Spatial autocorrelation analysis for the OMN1 population revealed no apparent deviation of Moran's I' values from zero until they fluctuated at the longest distance class $(85-90 \mathrm{~m})$, which contained only two pairs of individuals; alleles were randomly distributed within the OMN1 population.

\section{Discussion}

A direct comparison of microsatellite variation with other studies is problematic because different microsatellite loci may generate different levels of variation. However, a comparison with the results from a related species, $M$. 
Table 2 Number of alleles per locus $(A)$, average observed $\left(\mathrm{H}_{\mathrm{o}}\right)$ and expected $\left(\mathrm{H}_{\mathrm{e}}\right)$ heterozygosities, and fixation indices $\left(\mathrm{F}_{\mathrm{IS}}\right)$, with standard errors in parenthesis, in 19 populations of Magnolia sieboldii

\begin{tabular}{|c|c|c|c|c|}
\hline Population & $A$ (s.e.) & $H_{o}$ (s.e.) & $H_{e}$ (s.e.) & $F_{I S}$ \\
\hline AKS & $3.75(0.95)$ & $0.242(0.088)$ & $0.344(0.117)$ & $0.311^{* *}$ \\
\hline $\begin{array}{l}\text { HDK1 } \\
\text { HDK2 } \\
\text { Hodaka mean }\end{array}$ & $\begin{array}{c}2.50(0.29) \\
4.50(0.96) \\
3.50\end{array}$ & $\begin{array}{c}0.193(0.099) \\
0.196(0.062) \\
0.194\end{array}$ & $\begin{array}{c}0.309(0.119) \\
0.352(0.143) \\
0.330\end{array}$ & $\begin{array}{c}0.388^{* *} \\
0.453^{* *} \\
0.421\end{array}$ \\
\hline $\begin{array}{l}\text { OMN1 } \\
\text { OMN2 } \\
\text { OMN3 } \\
\text { OMN4 } \\
\text { OMN5 } \\
\text { OMN6 } \\
\text { OMN7 } \\
\text { Omine mean }\end{array}$ & $\begin{array}{c}3.50(0.65) \\
2.50(0.29) \\
3.50(0.50) \\
2.75(0.48) \\
2.50(0.50) \\
2.00(0.71) \\
3.00(0.41) \\
2.82\end{array}$ & $\begin{array}{c}0.490(0.112) \\
0.308(0.140) \\
0.368(0.085) \\
0.313(0.121) \\
0.280(0.132) \\
0.268(0.155) \\
0.232(0.084) \\
0.323\end{array}$ & $\begin{array}{c}0.524(0.109) \\
0.385(0.109) \\
0.420(0.095) \\
0.328(0.135) \\
0.303(0.145) \\
0.254(0.147) \\
0.406(0.114) \\
0.374\end{array}$ & $\begin{array}{c}0.073 \\
0.238^{*} \\
0.098 \\
0.055 \\
0.148 \\
-0.038 \\
0.457^{* *} \\
0.147\end{array}$ \\
\hline $\begin{array}{l}\text { ISZ1 } \\
\text { ISZ2 } \\
\text { ISZ3 } \\
\text { ISZ4 } \\
\text { ISZ5 } \\
\text { ISZ6 } \\
\text { ISZ7 } \\
\text { Isizuchi mean }\end{array}$ & $\begin{array}{c}5.25(0.65) \\
3.75(0.48) \\
4.50(0.50) \\
6.00(1.44) \\
4.25(0.75) \\
6.00(0.91) \\
2.75(0.25) \\
4.64\end{array}$ & $\begin{array}{c}0.492(0.068) \\
0.409(0.059) \\
0.463(0.109) \\
0.642(0.063) \\
0.331(0.094) \\
0.597(0.072) \\
0.292(0.109) \\
0.461\end{array}$ & $\begin{array}{c}0.645(0.070) \\
0.499(0.091) \\
0.555(0.108) \\
0.652(0.042) \\
0.378(0.117) \\
0.634(0.069) \\
0.308(0.122) \\
0.524\end{array}$ & $\begin{array}{l}0.256^{* *} \\
0.119 \\
0.149^{*} \\
0.021 \\
0.138^{*} \\
0.105^{* *} \\
0.074 \\
0.123\end{array}$ \\
\hline KMR & $4.75(1.03)$ & $0.560(0.080)$ & $0.615(0.061)$ & 0.107 \\
\hline KNM & 3.25 (1.44) & $0.273(0.177)$ & $0.265(0.163)$ & -0.020 \\
\hline mean & 3.73 & 0.360 & 0.427 & 0.174 \\
\hline
\end{tabular}

Levels of significance for $\mathrm{F}_{\mathrm{IS}}>0$ were determined after 1000 permutations: ${ }^{*} P<0.05 ;{ }^{* *} P<0.005$.

a
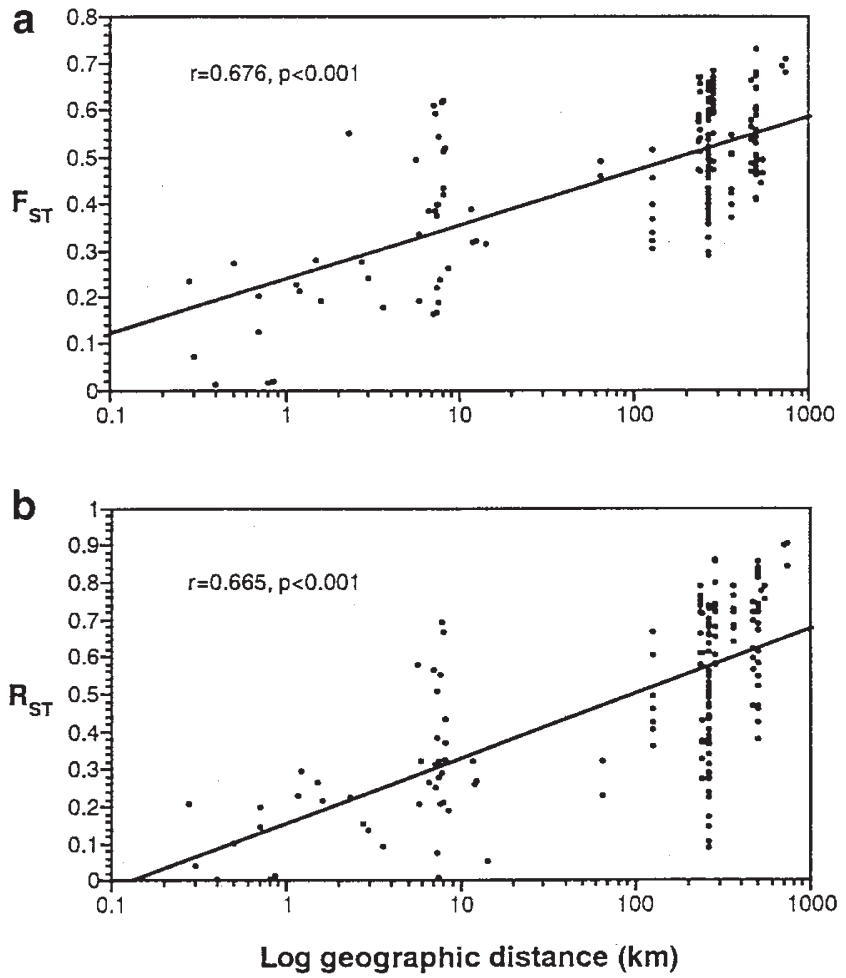

Figure 2 Correlation of genetic differentiation with geographic distance between populations of Magnolia sieboldii. Population differentiation was measured as pairwise $\mathrm{F}_{\mathrm{ST}}(\mathbf{a})$ and $\mathrm{R}_{\mathrm{ST}}(\mathbf{b})$. obovata, that includes the same four loci, will provide important evidence for evaluating the level of genetic diversity in M. sieboldii. Isagi et al (2000) detected an average of 24 alleles and a mean observed heterozygosity of $\mathrm{H}_{\mathrm{o}}=0.90$ for the same four loci in 83 adult trees within a plot. The level of allelic diversity in M. obovata not only far exceeded the level of population allelic richness in $M$. sieboldii, but also was higher than the total number of alleles found in this study, covering the nearly entire distribution of $M$. sieboldii.

The difference in total genetic variation between $M$. sieboldii and M. obovata could be attributed to biological factors and molecular properties. For the former, M. sieboldii might have suffered from historical bottlenecks at the species' level because of its restricted distribution. M. sieboldii populations are restricted to narrow ranges of habitat at the high elevation and are narrowly distributed along the ridges and rivers in backbones of western Japan. M. sieboldii is considered to be a relict (Ueda, 1980), and might have been bottlenecked severely through climate fluctuations.

For the latter, mutation pressure or ascertainment bias might lead to the lower levels of microsatellite variability in M. sieboldii. We had examined amplification of 11 microsatellite loci characterized for $M$. obovata in advance, and eight had produced polymorphic bands for M. sieboldii. They had been assayed for the OMN1 population, and the loci other than the four in this study had shown similar levels of polymorphism, with the number of alleles ranging from two to five. Four loci assayed in this study were neither the ones of lower variability in $M$. sieboldii nor the ones of higher variability in M. obovata in Isagi et al (2000). Thus, consistently lower variability 

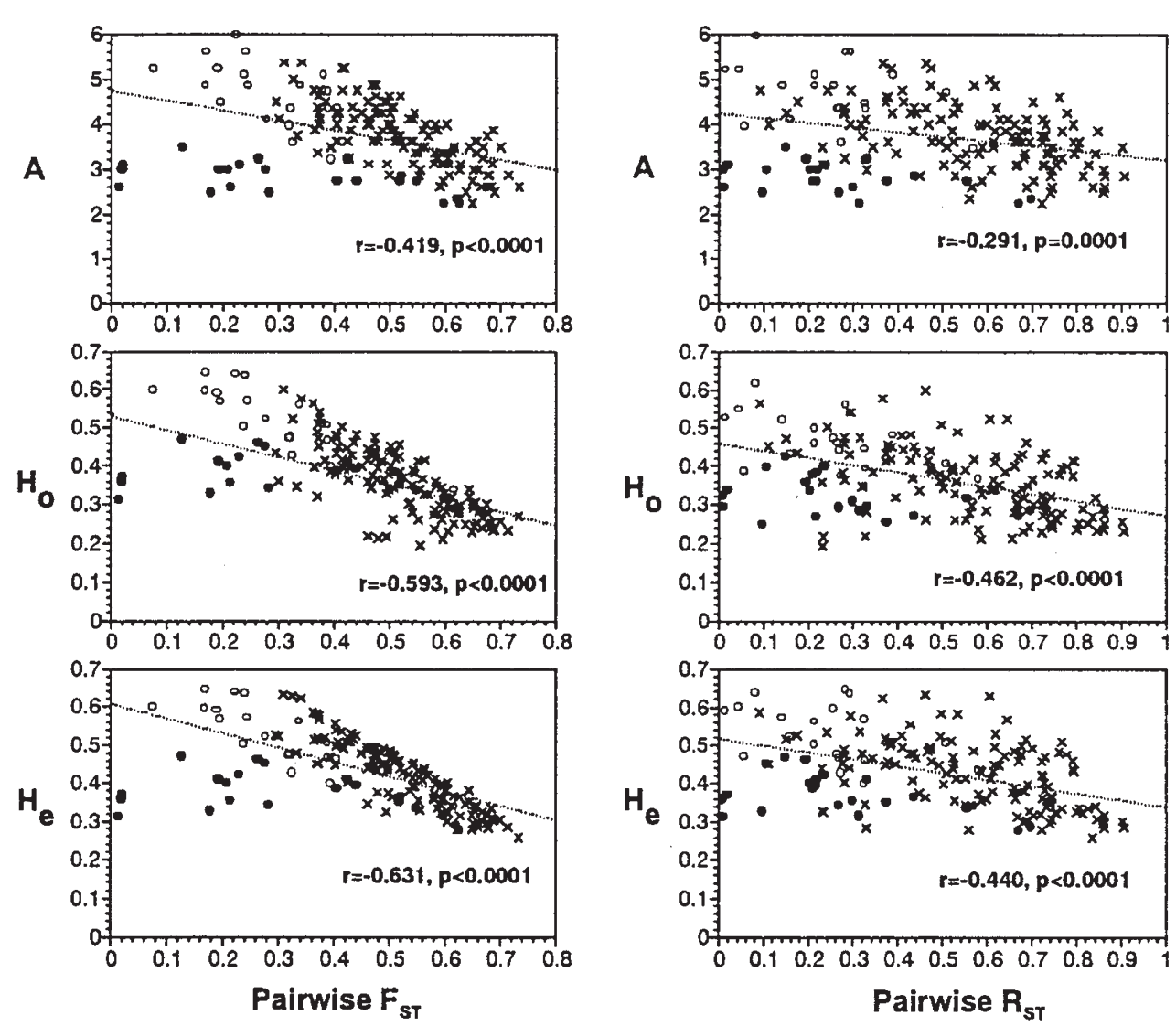

Figure 3 Relationships between population pairwise genetic differentiation and averaged genetic diversity in Magnolia sieboldii. Solid circles, open circles, and crosses indicate population pairs within the Ohmine region, within the Ishizuchi region, and pairs of populations belonging to different regions, respectively.

detected in $M$. sieboldii could not be attributed to ascertainment bias. It would be due to structural or other properties of microsatellite that differ between the two species. This agrees with the general trends in plants that amplification and polymorphism decrease with increasing evolutionary distance from the species from which microsatellite loci were isolated (eg, Dayanandan et al, 1997; Butcher et al, 2000). Allele size ranges in M. sieboldii were narrower at all of the four loci, and shifted to smaller size ranges at the loci M6D3 and M6D4, than those of $M$. obovata; PCR product size ranged from 270 bp to $304 \mathrm{bp}$ at M10D8, from $116 \mathrm{bp}$ to $138 \mathrm{bp}$ at M6D3, from $292 \mathrm{bp}$ to $314 \mathrm{bp}$ at M17D5 and from $144 \mathrm{bp}$ to 158 bp at M6D4 for M. sieboldii, while it ranged from $257 \mathrm{bp}$ to $313 \mathrm{bp}$ at M10D8, from $106 \mathrm{bp}$ to $198 \mathrm{bp}$ at M6D3, from $289 \mathrm{bp}$ to $317 \mathrm{bp}$ at M17D5 and from $146 \mathrm{bp}$ to $235 \mathrm{bp}$ at M6D4 for $M$. obovata. Smaller allele size in $M$. sieboldii suggests that fewer repeats at microsatellite motifs might contribute to lower mutation rate at microsatellite loci in $M$. sieboldii. Lower mutation rate could be also caused by interruption of repeat motifs in some of the loci. It is necessary for the microsatellite loci to be sequenced for M. sieboldii.

It is difficult to evaluate the relative importance of the biological and molecular factors in determining the overall level of genetic variation in $M$. sieboldii in Japan from the present data. Potential microsatellite variability in $M$. sieboldii spp. japonica may be estimated by surveying the same loci for $M$. sieboldii spp. sieboldii, which is a common species in the Korean Peninsula and thus more unlikely to have suffered from severe historical bottlenecks. Assuming that these subspecies are similar in the molecular properties at these microsatellite loci, and if the lower genetic variability in spp. japonica in this study resulted from historical bottlenecks with no or little mutation pressure at these loci, overall level of genetic variation at the same loci in spp. sieboldii, probably less bottlenecked historically, will be much more abundant than that in spp. japonica and nearer to the level in M. obovata.

At the intrapopulation level, genetic variation of $M$. sieboldii was low (Table 2). Although the problem of comparing other studies using different microsatellite loci remains as stated above, studies using microsatellites usually detect higher levels of intrapopulation genetic variation. For example, Streiff et al (1998) detected averages of 19.8 and 18.5 alleles per locus in two Quercus species, whilst Dow and Ashley (1996) detected an average of 18.25 alleles per locus in a third Quercus species. Population genetic variation in Swietenia humilis $(\mathrm{A}=7.05$, $\mathrm{H}_{\mathrm{o}}=0.482$; White et al, 1999) and the orchid, Gymnadenia conopsea $\left(\mathrm{A}=6.97\right.$ and $\mathrm{H}_{\mathrm{o}}=0.667$; Gustafsson, 2000), were slightly higher than the results in this study. Argyroxiphium sandwicense, a narrow endemic and severely bottlenecked species, had lower intrapopulation genetic variation than the result of this study $\left(\mathrm{A}=2.75, \mathrm{H}_{\mathrm{o}}=0.157\right.$; Friar et al, 2000).

The inbreeding coefficient $\left(\mathrm{F}_{\mathrm{IS}}\right)$ was positive in most populations (Table 2). Genetic substructuring within a 

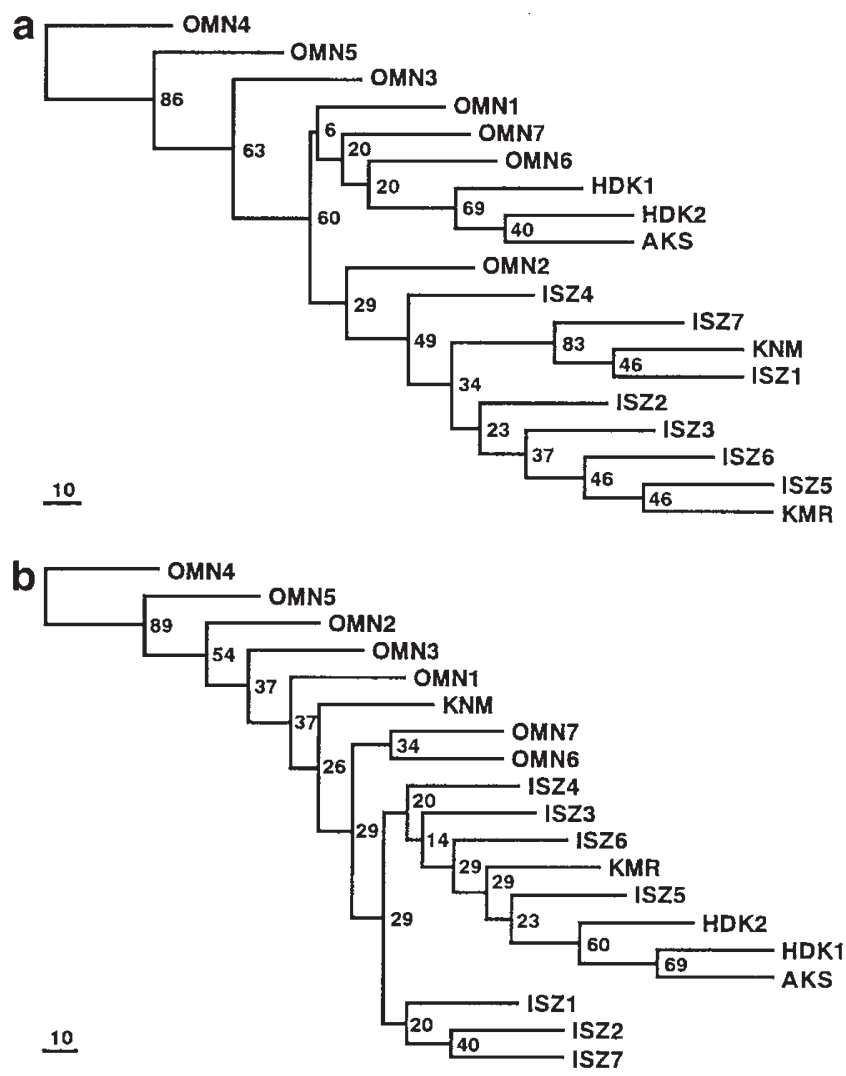

Figure 4 Neighbour-joining dendrograms relating 19 Magnolia sieboldii populations based on: (a) Nei's D and (b) Goldstein's $(\partial \mu)^{2}$. Population identification codes were according to Table 1. Bootstrap values (percentages) were computed over 35 replications by resampling loci.

population might lead to positive $\mathrm{F}_{\mathrm{IS}}$ (Wahlund effect), however, this probability can be excluded because the autocorrelation analysis of the OMN1 population revealed no evidence of spatial clustering of alleles. Thus the positive $F_{I S}$ in most populations suggested that excessive inbreeding was common in $M$. sieboldii. Although knowledge on reproductive traits of $M$. sieboldii was absent, it is reported that Magnolia flowers are generally protogynous (Thien, 1974) and that related Magnolia species are self-compatible (Ishida and Nagasaka, 1994; Ishida, 1996). Considering this, inbreeding is thought to be possible in $M$. sieboldii through geitonogamy, but not through autogamy. It was not clear whether inbreeding led to positive $\mathrm{F}_{\mathrm{IS}}$, since the extent of inbreeding depression is not known for $M$. sieboldii. Estimates of inbreeding depression was high in related species, $M$. obovata (Ishida and Nakamura, 1997), although genetic load might be purged in $M$. sieboldii because of its small population size. Positive $\mathrm{F}_{\mathrm{IS}}$ are probably due to an excess of geitonogamy over allogamy or accumulated inbreeding because of small population size.

Mean pairwise $F_{\mathrm{ST}}$ and $\mathrm{R}_{\mathrm{ST}}$ within regions (0.31 and 0.26), with a maximum distance of $14 \mathrm{~km}$ between populations, indicated that the level of local population differentiation could be regarded as high. Although microsatellite data on a comparable spatial scale for plants are limited, much lower differentiation is observed in S. humilis $\left(\mathrm{R}_{\mathrm{ST}}=0.032 ;\right.$ White et al, 1999) and G. conopsea $\left(\mathrm{F}_{\mathrm{ST}}=0.06, \mathrm{R}_{\mathrm{ST}}=0.02 ;\right.$ Gustafsson, 2000).
The mean values of pairwise differentiation among regions $\left(\mathrm{F}_{\mathrm{ST}}=0.52, \mathrm{R}_{\mathrm{ST}}=0.57\right)$ was similar to, though slightly higher than, the total genetic differentiation $\left(\mathrm{F}_{\mathrm{ST}}\right.$ $\left.=0.49, R_{\mathrm{ST}}=0.54\right)$. Similar levels of microsatellite differentiation were obtained across the entire worldwide range of some plant species, eg Zostera marina $\left(\mathrm{R}_{\mathrm{ST}}=0.384\right.$; Reusch et al, 2000) and Avicennia marina $\left(\mathrm{F}_{\mathrm{ST}}=0.410, \mathrm{R}_{\mathrm{ST}}\right.$ $=0.710$; Maguire et al, 2000). Thus the values of genetic differentiation detected in this study were considered to be notably high as the spatial scale among regions (up to $737 \mathrm{~km}$ ), suggesting the existence of severe genetic barriers among regions. For animals, a maximum $R_{\mathrm{ST}}$ of 0.568 was reported for natterjack toads among isolated regions on the spatial scale comparable to this study (Rowe et al, 1998).

Thus genetic structure in $M$. sieboldii was characterised by low genetic variation within populations, high genetic subdivision among regional populations and remarkable genetic differentiation among regions. Since populations of $M$. sieboldii were typically small and isolated, the low levels of population genetic variation and the high genetic differentiation among regional populations were probably due to stochastic loss of genetic variation by small population size, such as genetic drift and to some extent inbreeding, and limited gene flow (Ellstrand and Elam, 1993).

Some evidence suggests that the effect of genetic drift and limited gene flow were important. First, significant negative correlation between pairwise genetic differentiation and genetic variation averaged for the population pairs (Figure 3) indicated that populations suffering from the loss of genetic variation differentiated from other populations. It suggested that differentiating and lowering effects on population genetic variation, such as genetic drift, were very influential in determining the genetic structure.

Second, pairwise analysis on genetic and spatial distance revealed significant IBD models (Figure 2). The IBD models were still significant when only the population pairs within each region were analysed $\left(\mathrm{F}_{\mathrm{ST}}: r=0.619, P\right.$ $<0.0001 ; \mathrm{R}_{\mathrm{ST}}: r=0.475, P=0.013$; Figure 5). The significant IBD models at the regional scale suggested that genetic differentiation were counterbalanced by distancedependant gene flow and populations had reached near gene flow-drift equilibrium (Slatkin, 1993).

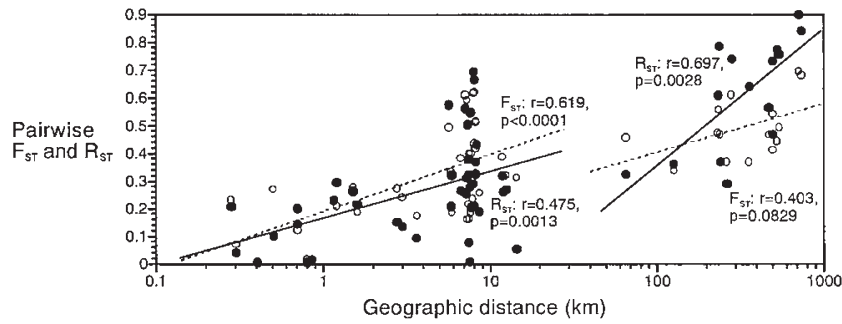

Figure 5 Relationships between pairwise genetic differentiation and spatial distance in Magnolia sieboldii. IBD models were tested separately, within regions $(<14 \mathrm{~km})$ and among regions. To test IBD models among regions, one population in each region, with the most variable loci and most unlikely to be suffered from genetic drift (OMN1 in the Ohmine, ISZ6 in the Ishizuchi and HDK2 in the Hodaka) was selected to represent regional genetic variation and the rests were removed from analysis. Open and shaded circles indicates the data points for pairwise $\mathrm{F}_{\mathrm{ST}}$ and $\mathrm{R}_{\mathrm{ST}}$, respectively. Regression lines are expressed as dotted for $\mathrm{F}_{\mathrm{ST}}$ and solid for $\mathrm{R}_{\mathrm{ST}}$. 
Third, those trends in genetic differentiation, the negative correlation between pairwise genetic distance and averaged genetic variation, and the IBD at the regional scales, were both clearer for $\mathrm{F}_{\mathrm{ST}}$ than for $\mathrm{R}_{\mathrm{ST}}$ (Figures 3 and 5). They could be attributed to the mutation model they assumed. Because the SMM, on which $\mathrm{R}_{\mathrm{ST}}$ was based, assumes contiguous allelic states at mutation-drift equilibrium (Slatkin, 1995), discontinuity in the distribution of allele length generated by random genetic drift might perturb $R_{\mathrm{ST}}$ values when genetic drift were more important than mutation (Gaggiotti et al, 1999; Balloux et $a l, 2000)$. Clearer IBD models for $F_{S T}$ based on the IAM may suggest relative importance of random genetic drift rather than mutation in generating this differentiation among regional populations. These evidences above suggested genetic drift and limited gene flow were important in determining genetic structure of $M$. sieboldii, at least on the regional spatial scales.

Microsatellite variation in $M$. sieboldii showed a remarkable hierarchical genetic structure; significant genetic differentiation among regional populations, further differentiation among regions and significant IBD models, although intrapopulational genetic structure was absent. This hierarchical structure would contribute to the regional genetic groups in neighbour-joining dendrograms, both using an IAM and an SMM. However, genetic relationships between regions were different among the mutation models (Figure 4). The neighbour-joining tree based on an SMM agreed better with the geographical origins of the populations than that based on an IAM. Since Goldstein's $(\partial \mu)^{2}$ is based on the lengths of microsatellites alleles, similarity in allele sizes across nearby regions might cause the neighbour-joining tree based on $(\partial \mu)^{2}$ to match their geographical relationships among regions.

This leads to an idea that a SMM was more appropriate to differentiate populations among regions in $M$. sieboldii than an IAM. We further tested IBD models among regions, by selecting one population in each region into analysis. In each of the three regions where more than one population were sampled (ie, the Ishizuchi, Ohmine and Hodaka regions), a population with the highest genetic diversity and thus most unlikely to have suffered from genetic drift (ie, the OMN1, the ISZ6 and the HDK2, respectively), was selected to represent regional genetic variation. The rest were removed from analysis, in order to reduce the effects of random genetic divergence among the regional populations on the IBD patterns. Pairwise $\mathrm{R}_{\mathrm{ST}}$ values were highly correlated with geographic distance $(r=0.697, P=0.0028)$, while pairwise $\mathrm{F}_{\mathrm{ST}}$ values were not significantly correlated $(r=0.403, P$ $=0.0829$ ) (Figure 5). The SMM might be more suited to explain the genetic structure among regions for $M$. sieboldii. $\mathrm{R}_{\mathrm{ST}}$ is a sensitive measure to estimate genetic differentiation among populations if microsatellite variation follows the SMM, but may be confused when the contiguous allele distribution is disturbed by random genetic drift. It is considered that mutation in microsatellite loci was more important in determining the genetic differentiation among regions for $M$. sieboldii than random genetic drift and gene flow.

Population genetic variation was relatively low in the Ohmine mountain range, especially compared with that in the Ishizuchi mountain range (Table 2). Even the largest known OMN1 population had smaller genetic vari- ation than that of most Ishizuchi populations. Total allele

richness and allele length variation were higher in the Ishizuchi mountain range than in the Ohmine range (Appendix). Moreover, lowered population genetic variation in the Ohmine populations was shown by the correlation between pairwise genetic differentiation and averaged genetic variation (Figure 3). These differences in the level of genetic variation among regions might be caused by some biological factors. For example, populations in a region may have experienced recent demographic changes. Gene flow might be more limited in the Ohmine region, by a difference in geographical isolation among regional populations, within-species variation in biological interactions such as pollination and seed dispersal, or other factors. Another possibility is that historical bottlenecks or founding events may have limited the allele richness in the Ohmine mountain range. In addition, the lower level of population genetic variation in the Ohmine might be due to mutation pressure at some microsatellite loci. However, the real factors that influenced the difference in the level of genetic variation among regions were unclear in this study.

\section{Conclusions}

\section{Implications for conservation}

The results reported here showed that microsatellite variation in small and isolated populations of $M$. sieboldii was relatively small. But microsatellite variation in $M$. sieboldii was thought to be still more informative than allozymes, for example in assessing the effect of genetic drift, because it was much higher than the mean level of allozyme genetic variation in long-lived plants (Loveless and Hamrick, 1984). The results also detected local genetic differentiation and geographical structures among regions, in spite of severe random genetic drift.

The data in this study suggested limited interpopulational gene flow, even among close populations; recolonization by a population is probably difficult once it disappears. It also suggested the existence of genetic barriers among regions. Regional populations with genetic remoteness may contain evolutionary distinctiveness, though neither morphological nor ecological variation in $M$. sieboldii has been reported. Although $M$. sieboldii is not included on the Ministry of the Environment's Red List, it is rare, and recently, even the largest Hakkyougatake (OMN1) populations have been severely damaged by herbivores. Both the conservation of existing populations and the conservation of the genetic distinctiveness of regions should be made priorities.

Especially, the importance of Ishizuchi populations, where higher genetic variation was found in this study, should be noticed for the conservation of genetic resource. In addition, understanding the factors lowering the level of genetic variation in the Ohmine region will be important in managing populations of $M$. sieboldii. For instance, if differences in the level of genetic diversity among regions reflected differences in current interpopulational gene flow among regional populations, then conservation of the process that maintained the higher levels of gene flow among the Ishizuchi populations, will be necessary to maintain populations' chances of survival or recolonization. The factors that might change the level of genetic variation of a population and a region remain to be solved. 
These results showed the potential of hypervariable microsatellite loci to evaluate the effects of genetic drift and population isolation within regions, and to detect genetic distinctiveness, in spite of the loss of overall genetic variation in $M$. sieboldii.

\section{Acknowledgements}

We are very grateful to Hiromitsu Matsui for providing us with information on $M$. sieboldii populations. We also thank Keiji Odani, Hideo Tabata and Tohru Nakashizuka for their valuable comments and encouragement.

\section{References}

Balloux F, Brünner H, Lugon-Moulin N, Jacques H, Goudet J (2000). Microsatellite can be misleading: an empirical and simulation study. Evolution 54: 1414-1422.

Bauert MR, Kälin M, Baltisberger M, Edwards PJ (1998). No genetic variation detected within isolated relict populations of Saxifraga cernua in the Alps using RAPD markers. Mol Ecol 7: 1519-1527.

Butcher PA, Decroocq S, Gray Y, Moran GF (2000). Development, inheritance and cross-species amplification of microsatellite markers from Acacia mangium. Theor Appl Genet 101: 1282-1290.

Dow BD, Ashley MV (1996). Microsatellite analysis of seed dispersal and parentage of saplings in bur oak, Quercus macrocarpa. Mol Ecol 5: 615-627.

Ellstrand NC, Elam DR (1993). Population genetic consequences of small population size: Implications for plant conservation. Ann Rev Ecol Syst 34: 217-242.

Felsenstein J (1989). PHYLIP - Phylogeny Inference Package (Version 3.2). Cladistics 5: 164-166.

Friar EA, Ladoux T, Roalson EH, Robichaux RH (2000). Microsatellite analysis of a population crash and bottleneck in the Mauna Kea silversword, Argyroxiphium sandwicense ssp. sandwicense (Asteraceae), and its implications for reintroduction. Mol Ecol 9: 2027-2034.

Gaggiotti OE, Lange O, Rassmann K, Gliddon C (1999). A comparison of two indirect methods for estimating average levels of gene flow using microsatellite data. Mol Ecol 8: 1513-1520.

Goldstein DB, Linares AR, Cavalli-Sforza LL, Feldman MW (1995). Genetic absolute dating based on microsatellite and the origin of modern humans. Proc Natl Acad Sci USA 92: 6723-6727.

Goodman SJ (1997). $\mathrm{R}_{\mathrm{ST}}$ Calc: a collection of computer programs for calculating estimates of genetic differentiation from microsatellite data and determining their significance. Mol Ecol 6: 881-885.

Goudet J (1995). Fstat version 1.2: a computer program to calculate F-statistics. J Heredity 86: 485-486.

Gustafsson S (2000). Patterns of genetic variation in Gymnadenia conopsea, the fragmented orchid. Mol Ecol 9: 1863-1872.

Hughes CR, Queller DC (1993). Detection of highly polymorphic microsatellite loci in a species with little allozyme polymorphism. Mol Ecol 2: 131-137.

Isagi Y, Kanazashi T, Suzuki W, Tanaka H, Abe T (1999). Polymorphic microsatellite DNA markers for Magnolia obovata Thunb. and their utility in related species. Mol Ecol 8: 698-700.

Isagi Y, Kanazashi T, Suzuki W, Tanaka H, Abe T (2000). Microsatellite analysis of the regeneration process of Magnolia obovata Thunb. Heredity 84: 143-161.

Ishida K (1996). Beetle pollination of Magnolia praecocissima var. borealis. Plant Species Biol 11: 199-206.

Ishida K, Nagasaka K (1994). Reproductive characteristics of
Magnolia hypoleuca (1) Estimation of selfing rate by means of isozyme analysis. Trans Jap For Soc 105: 295-296.

Ishida K, Nakamura K (1997). Outcrossing rate and inbreeding depression in natural populations of Magnolia hypoleuca. Am J Bot 84 (Suppl Abstracts): 121.

Ledig FT, Conkle MT (1983). Gene diversity and genetic structure in a narrow endemic, torrey pine (Pinus torreyana Parry ex. Carr.). Evolution 37: 79-85.

Loveless MD, Hamrick JL (1984). Ecological determinants of genetic structure in plant populations. Ann Rev Ecol Syst 15: 65-95.

Maguire TL, Saenger P, Baverstock P, Henry R (2000). Microsatellite analysis of genetic structure in the mangrove species Avicennia marina (Forsk.) Vierh. (Avicenniaceae). Mol Ecol 9: 1853-1862.

Miller MP (1997). Tools for population genetic analysis [TFPGA] 1.3: a Windows program for population genetic data. Computer software distributed by author.

Milligan B (1992). Plant DNA isolation. In: Hoelzel AR (ed) Molecular Genetic Analysis of Populations: Practical Approach, IRL Press: Oxford, pp 59-88.

Nei M (1978). Estimation of average heterozygosity and genetic distance from a small number of individuals. Genetics 89: 583-590.

Van Oppen MJH, Turner GF, Rico C, Deutsch JC, Ibrahim KM, Robinson RL et al (1997). Unusually fine-scale genetic structuring found in rapidly speciating Malawi cichlid fishes. Proc $R$ Soc Lond B 264: 1803-1812.

Reusch TBH, Stam WT, Olsen JL (2000). A microsatellite-based estimation of clonal diversity and population subdivision in Zostera marina, a marine flowering plant. Mol Ecol 9: 127-140.

Rowe G, Beebee TJC, Burke T (1998). Phylogeography of the natterjack toad Bufo calamita in Britain: genetic differentiation of native and translocated populations. Mol Ecol 7: 751-760.

Slatkin M (1993). Isolation by distance in equilibrium and nonequilibrium populations. Evolution 47: 264-279.

Slatkin M (1995). A measure of population subdivision based on microsatellite allele frequencies. Genetics 139: 457-462.

Sokal RR, Oden NL (1978). Spatial autocorrelation in biology 1. Methodology. Biol J Linn Soc 10: 199-228.

Streiff R, Labbe T, Bacilieri R, Steinkellner H, Glössl J, Kremer A (1998). Within-population genetic structure in Quercus robur L. and Quercus petraea (Matt.) Liebl. assessed with isozymes and microsatellites. Mol Ecol 7: 317-328.

Thien LB (1974). Floral biology of Magnolia Am J Bot 61: 10371045.

Ueda K (1980). Taxonomic study of Magnolia sieboldii C. Koch. Acta Phytotax Geobot 31: 117-125.

Valdes AM, Slatkin M, Freimer NB (1993). Allele frequencies at microsatellite loci: the stepwise mutation model revisited. Genetics 133: 737-749.

Vogel JC, Rumsey FJ, Russell SJ, Cox CJ, Holmes JS, Bujnoch W et al (1999). Genetic structure, reproductive biology and ecology of isolated populations of Asplenium csikii (Aspleniaceae, Pteridophyta). Heredity 83: 604-612.

Weir BS, Cockerham CC (1984). Estimating F-statistics for the analysis of population structure. Evolution 38: 1358-1370.

White GM, Boshier DH, Powell W (1999). Genetic variation within a fragmented population of Swietenia humilis Zucc. Mol Ecol 8: 1899-1909.

Widmer A, Schmid-Hempel P (1999). The population genetic structure of a large temperate pollinator species, Bombus pascuorum (Scopoli) (Hymenoptera: Apidae). Mol Ecol 8: 387-398.

\section{Appendix}

Allele frequencies at the 19 populations in $M$. sieboldii. The names of alleles were expressed as the PCR product size. Population identifications were according to Table 1. 


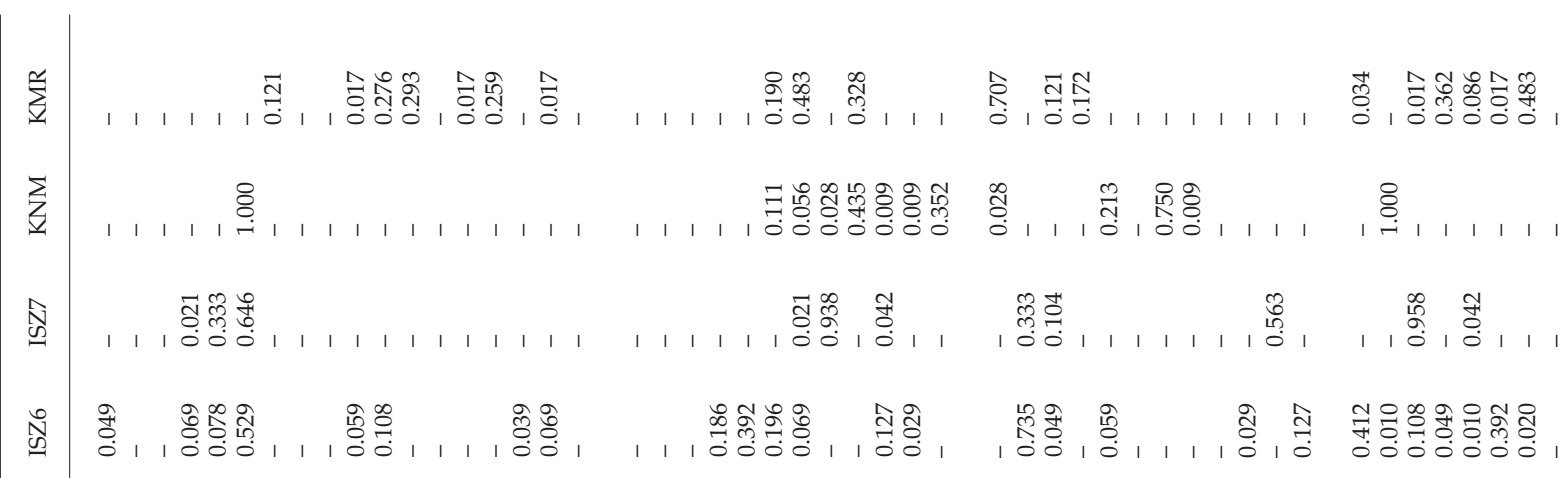

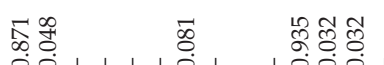
, 1000

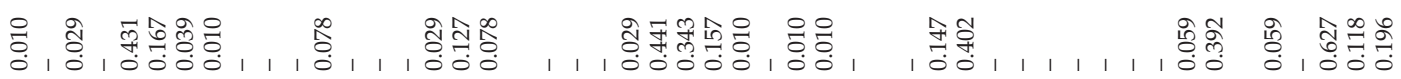

